\title{
Real-time PCR reveals a high incidence of Symbiodinium clade $D$ at low levels in four scleractinian corals across the Great Barrier Reef: implications for symbiont shuffling
}

\author{
J. C. Mieog • M. J. H. van Oppen · N. E. Cantin • \\ W. T. Stam $\cdot$ J. L. Olsen
}

Received: 28 November 2006/Accepted: 30 April 2007/Published online: 6 June 2007

(C) Springer-Verlag 2007

\begin{abstract}
Reef corals form associations with an array of genetically and physiologically distinct endosymbionts from the genus Symbiodinium. Some corals harbor different clades of symbionts simultaneously, and over time the relative abundances of these clades may change through a process called symbiont shuffling. It is hypothesized that this process provides a mechanism for corals to respond to environmental threats such as global warming. However, only a minority of coral species have been found to harbor more than one symbiont clade simultaneously and the current view is that the potential for symbiont shuffling is limited. Using a newly developed real-time PCR assay, this paper demonstrates that previous studies have underestimated the presence of background symbionts because of the low sensitivity of the techniques used. The assay used here targets the multi-copy rDNA ITS1 region and is able to detect Symbiodinium clades C and D with $>100$-fold higher sensitivity compared to conventional techniques. Technical considerations relating to intragenomic variation, estimating copy number and non-symbiotic contamination are discussed. Eighty-two colonies from four common scleractinian species (Acropora millepora,
\end{abstract}

Communicated by Editor in Chief: B. E. Brown.

J. C. Mieog $(\varangle)$ · M. J. H. van Oppen · N. E. Cantin

Australian Institute of Marine Science, PMB No 3,

Townsville 4810 MC, QLD, Australia

e-mail: J.C.Mieog@rug.nl

J. C. Mieog · W. T. Stam · J. L. Olsen

Department of Marine Benthic Ecology and Evolution,

Centre for Ecological and Evolutionary Studies,

Biological Centre, University of Groningen,

P.O. Box 14, 9750 AA Haren, The Netherlands
Acropora tenuis, Stylophora pistillata and Turbinaria reniformis) and 11 locations on the Great Barrier Reef were tested for background Symbiodinium clades. Although these colonies had been previously identified as harboring only a single clade based on SSCP analyses, background clades were detected in $78 \%$ of the samples, indicating that the potential for symbiont shuffling may be much larger than currently thought.

Keywords Coral $\cdot$ Symbiodinium $\cdot$ Zooxanthella . Background clade $\cdot$ Shuffling $\cdot$ Real-time PCR

\section{Introduction}

Many marine invertebrates and protists (e.g., corals, anemones, jelly fish, giant clams, and Foraminifera) form obligate mutualistic symbioses with algae of the genus Symbiodinium. The genus is several tens of millions of years old and comprises eight phylogenetic clades $(\mathrm{A}-\mathrm{H})$ based on ribosomal and chloroplast DNA (Pochon et al. 2006). Each clade encompasses multiple strains or types (Baker 2003; Coffroth and Santos 2005). The high diversity of Symbiodinium is often linked to physiological performance. In vitro studies using genetically distinct Symbiodinium cultures have found differences in photoacclimatory responses to light (Iglesias-Prieto and Trench 1997) and in growth (Kinzie et al. 2001; Robison and Warner 2006). Freshly isolated symbionts from different host species have shown distinct responses to heat-stress (Bhagooli and Hidaka 2003). In hospite, the genetic identity of the symbionts has been linked to a two to threefold difference in growth rates (Little et al. 2004) and $1-1.5^{\circ} \mathrm{C}$ difference in heat-tolerance (Rowan 2004; Berkelmans and van Oppen 2006) within a coral species. These results show 
that changes in a coral's zooxanthella community may result in changes in the physiology of the symbiosis.

There are two proposed ways by which changes in the symbiont population can occur: symbiont switching and symbiont shuffling (Baker 2003). Symbiont switching is the uptake of a new symbiont type from the environment, whereas in symbiont shuffling, the new symbiont does not come de novo from the environment, but is already present at low abundance in the coral tissues. Uptake of exogenous zooxanthellae by adult individuals has been shown experimentally in anemones (Kinzie et al. 2001) and in a soft coral (Lewis and Coffroth 2004), but has so far not been observed in scleractinian corals. Instead, a coral's temporal window for uptake of zooxanthellae may be narrow and restricted to the juvenile stage (Little et al. 2004). Symbiont shuffling may play an important role in scleractinian corals, as recent studies have shown that resident algal populations consisting of more than one type of alga may change in relative abundance: (1) on a seasonal basis (Chen et al. 2005); (2) while recovering from a natural bleaching event (Thornhill et al. 2006b); and (3) after bleaching following transplantation (Berkelmans and van Oppen 2006).

In a recent review, Goulet (2006) surveyed 442 species of both hard and soft corals from 43 published studies in the literature and concluded that the simultaneous occurrence of multiple symbiont clades is low (23\%) and, therefore, the promise of symbiont shuffling as a mechanism to cope with climate change, has been overestimated. While their conclusion is consistent with current data, absence of evidence is not necessarily evidence of absence. This study investigated whether the low value is an artifact caused by the low sensitivity of the most commonly used survey techniques for symbiont detection: denaturing gradient gel electrophoresis (LaJeunesse 2002), single strand conformational polymorphism (Fabricius et al. 2004), restriction fragment length polymorphism (Diekmann et al. 2002), and DNA fingerprinting (Goulet and Coffroth 2003a). None of these methods can detect clades, which are present at levels below $5-10 \%$ of the total symbiont population, and direct sequencing of PCR products will also only detect the dominant symbiont.

Here, a highly sensitive, real-time PCR assay is presented that quantifies the nuclear ribosomal DNA (nrDNA) Internal Transcribed Spacer 1 (ITS1) of clade C symbionts versus clade $\mathrm{D}$ symbionts within a single sample. The goal is to provide a new tool for a reassessment of the presence of low abundance, background or cryptic clades. The new assay was tested by resurveying a set of samples that were previously identified as having a single symbiont clade based on SSCP analyses and by verifying the nrDNA results with a similar assay based on chloroplast DNA. The implications of the results are discussed in terms of the current view about the importance of symbiont shuffling, and in terms of the prevalence and significance of cryptic symbionts.

\section{Materials and methods}

Collection and preparation of the coral samples

A collection of 82 scleractinian coral samples spanning 11 locations and 4 species (Fig. 1, Table 1) was assayed for background clades. Small pieces were taken from 2 5 colonies/species and fixed in absolute ethanol. DNA was extracted using the DNeasy tissue kit (Qiagen) following the manufacturer's protocol for animal tissues and using $150 \mu$ lelution buffer. The DNA samples were the same as those used in van Oppen et al. (2005) (Acropora millepora, Acropora tenuis and Stylophora pistillata), and in Ulstrup et al. (2006) (Turbinaria reniformis).

The real-time PCR assay

Clade C- and clade D-specific ITS1 primer pairs were obtained from Ulstrup and van Oppen (2003) (Table 2). A $25 \mu$ real-time PCR reaction contained: $1 \times$ IQ SYBR Green supermix (BioRAD), $180 \mathrm{nM}$ clade Symbiodiniumuniversal forward primer, $180 \mathrm{nM}$ clade $\mathrm{C}$ - or D-specific reverse primer and $2.5 \mu \mathrm{l}$ coral DNA template (MilliQ $\mathrm{H}_{2} \mathrm{O}$ in case of no-template controls). Amplifications were run on the ICycler IQ Real-Time PCR Detection System (BioRAD). After an initial heating step to activate the Taqpolymerase following the manufacturer's instructions, the

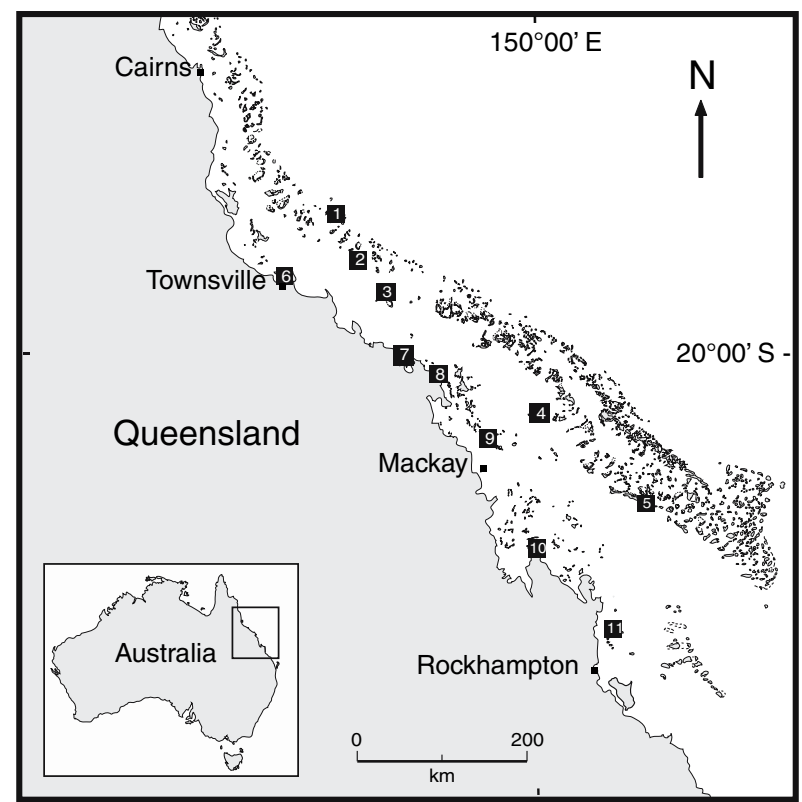

Fig. 1 Sampling locations. See Table 1 for location names, coordinates and sampling numbers 
Table 1 Species, locations and symbiont types/clades based on SSCP and real-time PCR

\begin{tabular}{|c|c|c|c|c|c|}
\hline Species & Location name & Lat-long & Fig. 1 & $\begin{array}{l}\text { Dominant type } \\
\text { based on } \mathrm{SSCP}^{\mathrm{a}}\end{array}$ & $\begin{array}{l}\text { Dominant clade, back-ground } \\
\text { clade based on real-time PCR }\end{array}$ \\
\hline \multirow[t]{7}{*}{ Acropora millepora } & Chicken Reef & $18.5 \mathrm{~S}, 147.5 \mathrm{E}$ & 1 & $\mathrm{C} 2(2)^{1}$ & $\mathrm{C}(2)^{1}, \mathrm{D}(1)^{2}$ \\
\hline & Darley Reef & $19.1 \mathrm{~S}, 148.1 \mathrm{E}$ & 3 & C2 (5) & $C(5), D(5)$ \\
\hline & Stone Island & $20.0 \mathrm{~S}, 148.2 \mathrm{E}$ & 7 & $\mathrm{D}(4)$ & $\mathrm{D}(4), \mathrm{C} 2$ (4) \\
\hline & & & & C2 (1) & $C(1), D(1)$ \\
\hline & Credlin Reef & $20.3 \mathrm{~S}, 150.0 \mathrm{E}$ & 4 & C2 (5) & $C(5), D(5)$ \\
\hline & Miall Island & $23.1 \mathrm{~S}, 150.5 \mathrm{E}$ & 11 & $\mathrm{C} 1, \mathrm{C} 2$ (2) & $C(2), D(2)$ \\
\hline & & & & $\mathrm{D}(2)$ & $\mathrm{D}(2), \mathrm{C}(2)$ \\
\hline \multirow[t]{4}{*}{ Acropora tenuis } & Chicken Reef & $18.5 \mathrm{~S}, 147.5 \mathrm{E}$ & 1 & C2 (5) & $C(5), D(3)$ \\
\hline & Darley Reef & $19.1 \mathrm{~S}, 148.1 \mathrm{E}$ & 3 & C2 (5) & $C(5), D(4)$ \\
\hline & Credlin Reef & $20.3 \mathrm{~S}, 150.0 \mathrm{E}$ & 4 & $\mathrm{C} 1, \mathrm{C} 2, \mathrm{C} 3(5)$ & $C(5), D(4)$ \\
\hline & Miall Island & $23.1 \mathrm{~S}, 150.5 \mathrm{E}$ & 11 & C1 (3) & $C(3), D(2)$ \\
\hline \multirow[t]{5}{*}{ Stylophora pistillata } & Chicken Reef & $18.5 \mathrm{~S}, 147.5 \mathrm{E}$ & 1 & $\mathrm{C} 1, \mathrm{Cn}(5)$ & $C(5), D(3)$ \\
\hline & Darley Reef & $19.1 \mathrm{~S}, 148.1 \mathrm{E}$ & 3 & C1, Cn (4) & $C(4), D(4)$ \\
\hline & Credlin Reef & $20.3 \mathrm{~S}, 150.0 \mathrm{E}$ & 4 & Cn (5) & $C(5), D(5)$ \\
\hline & Brampton Island & $20.5 \mathrm{~S}, 149.2 \mathrm{E}$ & 9 & C1 (3) & $C(3), D(3)$ \\
\hline & Mumford Island & $22.0 \mathrm{~S}, 149.5 \mathrm{E}$ & 10 & $\mathrm{C} 1, \mathrm{Cn}(5)$ & $C(5), D(5)$ \\
\hline \multirow[t]{5}{*}{ Turbinaria reniformis } & Big Broadhurst Reef & $18.5 \mathrm{~S}, 147.4 \mathrm{E}$ & 2 & C1 (4) & $C(4), D(1)$ \\
\hline & Magnetic Island & $19.1 \mathrm{~S}, 147.5 \mathrm{E}$ & 6 & C1 (5) & $\mathrm{C}(5), \mathrm{D}(3)$ \\
\hline & Grassy Island & $20.1 \mathrm{~S}, 148.4 \mathrm{E}$ & 8 & C1 (4) & $\mathrm{C}(4), \mathrm{D}(2)$ \\
\hline & Heralds Reef Prong & $21.3 \mathrm{~S}, 151.2 \mathrm{E}$ & 5 & C1 (3) & $C(3), D(2)$ \\
\hline & Miall Island & $23.1 \mathrm{~S}, 150.5 \mathrm{E}$ & 11 & C1 (5) & C(5), D (3) \\
\hline
\end{tabular}

$(n)^{1}=$ number of samples analyzed, $(n)^{2}=$ number of samples with a background clade

${ }^{a}$ van Oppen et al. (2005) and Ulstrup and van Oppen (2003)

Table 2 Nuclear and chloroplast primers used in real-time PCR

${ }^{\text {a }}$ Ulstrup and van Oppen (2003)

\begin{tabular}{ll}
\hline Primer & Sequence \\
\hline nITS1 universal forward $^{\mathrm{a}}$ & 5'-AAGGAGAAGTCGTAACAAGGTTTCC-3' $^{\prime}$ \\
nITS1 C-specific reverse $^{\mathrm{a}}$ & 5'-AAGCATCCCTCACAGCCAAA-3' $^{\prime}$ \\
nITS1 D-specific reverse $^{\mathrm{a}}$ & 5'-CACCGTAGTGGTTCACGTGTAATAG-3' $^{\prime}$ \\
cp23S C forward & 5'-GGGATAAAACTTGGGTAACATTC-3' $^{\prime}$ \\
cp23S C reverse & 5'-CCAATTAAACAGTGGTCTTAGGAG-3' $^{\prime}$ \\
cp23S D forward & 5'-AACCCCCGATTGGCCTAG-3' $^{\prime}$ \\
cp23S D reverse & 5'CTTGATTGGGCCATTAAGCA-3' $^{\prime}$ \\
\hline
\end{tabular}

profile consisted of: 40 two-step cycles of $15 \mathrm{~s}$ at $95^{\circ} \mathrm{C}$ and $1 \mathrm{~min}$ at $60^{\circ} \mathrm{C}$. At the end of each run, a melt curve was generated by starting at $60^{\circ} \mathrm{C}$ and increasing the temperature by $0.5^{\circ} \mathrm{C}$ each $5 \mathrm{~s}$ for 70 cycles. Data collection took place during the $1 \mathrm{~min}$ at $60^{\circ} \mathrm{C}$ in each cycle, and during each temperature step of the melt curve.

The cycle-threshold $\left(C_{\mathrm{T}}\right)$ is the PCR cycle at which the fluorescence of a sample exceeds the chosen threshold limit. Setting the fluorescent threshold to a fixed value allows the comparisons of $C_{\mathrm{T}}$ values between runs. Duplicate clade $\mathrm{C}$ and $\mathrm{D}$ reactions were run for each sample along with negative (no-template) and positive controls in each run. The positive controls showed distinct peaks in the melt curve for clades $\mathrm{C}$ and $\mathrm{D}$. Any runs with peaks not within $1^{\circ} \mathrm{C}$ of these temperatures were discarded as having primer dimer signals (which occurred rarely). In some runs, the no-template controls showed a small signal during the last few cycles of the run, which is common in real-time PCR and caused by the formation of non-specific fluorescence. To avoid the inclusion of false positives, the end of the detection range was set three cycles prior to the $C_{\mathrm{T}}$ of the no-template controls that showed a non-specific fluorescence signal. Samples with $C_{\mathrm{T}}$ 's above the cut-off were treated as false positives and scored as no background clade present. Runs were analyzed using the IQ software V3.1 (BioRAD). 
$\mathrm{D}: \mathrm{C}$ cell number ratios were calculated using the formula: $\mathrm{D}: \mathrm{C}=\left(2^{C_{\mathrm{T}}(\mathrm{C})-C_{\mathrm{T}}(\mathrm{D})}\right) / \mathrm{K}^{\mathrm{DC}}$, where $C_{\mathrm{T}}(\mathrm{C})$ is the threshold cycle for the clade $\mathrm{C}$ specific reaction, $C_{\mathrm{T}}(\mathrm{D})$ the threshold cycle for the clade $\mathrm{D}$ specific reaction, and $\mathrm{K}^{\mathrm{DC}}$ the ratio of average copy number per cell between clades D and $C$ (see next subheading). The average D:C cell number ratio and SE were calculated for each species per location, including the samples in which no backgrounds were detected as zero. A typical run for one coral sample including calculations is shown in Fig. 2.

\section{Estimating average copy number}

Ribosomal DNA loci can exhibit large variations in copy numbers between individuals (Zhang et al. 1990; Rogers and Bendich 1987; Govindaraju and Cullis 1992) thus affecting the translation from ITS1 copy number ratios to cell number ratios. To assess the extent of this potential bias, the cell-to-cell copy number variability within a $\mathrm{C}$ and D-dominated coral colony was investigated, and the average copy number differences between colonies was determined from bulk cell analyses.

The cell-to-cell variability of ITS1 copy numbers within a clade was measured in a clade $\mathrm{C}$-only and clade D-only population using single-cell real-time PCR. Clade $\mathrm{C}$ and clade D zooxanthellae were isolated from $A$. tenuis and A. millepora, respectively, obtained from Magnetic Island. Coral tissue was airbrushed off the skeleton into $1 \mu \mathrm{m}$ filtered seawater (FSW). The slurry was spun down (400 g, $5 \mathrm{~min}$ ) and the zooxanthella pellet washed three times with FSW. Cell suspensions were quantified using a haemocytometer and diluted in FSW to one cell per $2 \mu \mathrm{l}$. Ten microliter were pipetted onto a microscope slide and viewed under a dissecting microscope (70× magnification). Single cells were then collected in $0.5 \mu$ of FSW using a pipette with a heat-elongated plastic pipette tip (to narrow the diameter of the tip), and were added directly to the realtime PCR reaction mix, which were thoroughly mixed by pipetting.

The $20 \mu \mathrm{l}$ PCR reactions consisted of: $180 \mathrm{nM}$ universal Forward Primer (uFP), 180 nM C- or D-specific Reverse Primer (RP), $1 \times$ SYBR Green PCR master mix (ABI), and $0.5 \mu \mathrm{l}$ FSW containing one zooxanthella. Runs were performed on a Rotor-Gene RG-3000A (Corbett Research) and analyzed using the Rotor-Gene v6.0 software. The reaction profile was the same as described in the previous section. A standard curve was prepared from purified PCR products of ITS1 with known DNA concentrations. DNA used for the standard curves was diluted in MilliQ with $20 \%$ FSW to compensate for the FSW added to the single cell reactions.

To obtain an indication of average copy numbers per clade, zooxanthellae were isolated and quantified from four C-dominated $(2 \times$ A. millepora, $1 \times$ A. tenuis and $1 \times$ Pocillopora damicornis) and two D-dominated $(2 \times$ A. millepora) colonies as described above. An aliquot containing 100,000 cells was spun down (5 min, $400 \mathrm{~g}$ ) and the DNA extracted following an adapted version of a method used for the black tiger shrimp, Penaeus monodon (Wilson et al. 2002). DNA isolations were performed in duplicate, and DNA pellets were dissolved in $200 \mu \mathrm{l}$ $0.01 \mathrm{M}$ Tris buffer $\mathrm{pH}$ 9. Two microliter template was used in the real-time PCR reaction mixes, which were prepared and run as described above. Values were calculated against

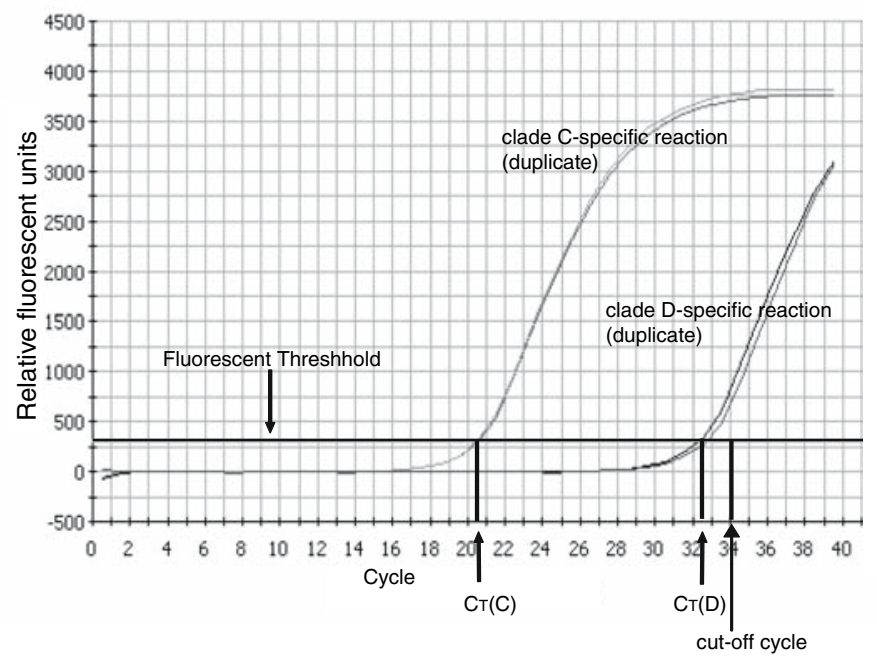

Fig. 2 A typical real-time PCR profile for the detection of a clade D background in a clade $\mathrm{C}$ dominated coral sample. The D-specific amplications begin later indicating the low, background abundance of this clade. The $\mathrm{D}: \mathrm{C}$ cell $\mathrm{nr}$. ratio is calculated as: $\mathrm{D}: \mathrm{C}=\left(2^{C_{\mathrm{T}}(\mathrm{C})-C_{\mathrm{T}}(\mathrm{D})}\right) / \mathrm{K}^{\mathrm{DC}}=2^{(20.5-32.5)} / 3=8.1 \times 10^{-5}$. The sensitivity for this sample is $2^{(20.5-34)} / 3=2.9 \times 10^{-5}=0.003 \%$ 
the standard curve (diluted with $0.01 \mathrm{M}$ Tris buffer $\mathrm{pH}$ 9) and divided by 1,000 (only $1 / 100$ of the sample was used in the PCR) to obtain the mean ITS1 copy number per cell per colony.

\section{Intragenomic variation}

Ribosomal DNA copies within a genome evolve in concert (Arnheim et al. 1980), usually resulting in rapid sequence homogenization within individuals and populations through gene conversion and unequal crossing over (Dover 1982). However, the homogenization is assumed not to be complete in Symbiodinium (Apprill and Gates 2007) and the occurrence of intragenomic variants may affect the real-time PCR assay if they interfere with the correct binding of the clade $\mathrm{C}$ - and clade $\mathrm{D}$-specific primers. To ensure that detected background clades were not due to intragenomic variants of ITS1 or real-time PCR artifacts, and to cross-test the accuracy of our ITS1 real-time PCR assay, 12 coral samples were re-analyzed using a second real-time PCR assay.

The 23S region of the chloroplast ribosomal DNA was quantified using two separate primer pairs (Table 2). Invitrogen's Platinum SYBR green $2 \times$ PCR mastermix was used as more consistent results were obtained in this assay with this mastermix than with the ABI real-time PCR mastermix. The $20 \mu \mathrm{l}$ reactions contained: $400 \mathrm{nM} \mathrm{C}$ - or $\mathrm{D}$-specific forward primer, $400 \mathrm{nM} \mathrm{C}$ - or D-specific reverse primer, $1 \times$ Platinum SYBR Green PCR master mix, $2 \mu \mathrm{l}$ template. Cycle conditions were: $2 \mathrm{~min}$ at $50^{\circ} \mathrm{C}, 2 \mathrm{~min}$ at $95^{\circ} \mathrm{C}$, followed by $15 \mathrm{~s}$ at $95^{\circ} \mathrm{C}$ and $30 \mathrm{~s}$ at $60^{\circ} \mathrm{C}$ for 40 cycles. Calculations were identical to the ITS1 assay except that no $\mathrm{K}^{\mathrm{DC}}$ was used.

\section{Results}

Specificity, efficiency and sensitivity of the ITS1 real-time PCR assay

An initial PCR amplification of cloned clade C and D ITS1 PCR products (i.e., using plasmids as template) verified that the clade $\mathrm{C}$ and $\mathrm{D}$ reactions were specific to their respective clades. The fluorescent threshold was set at 300 relative fluorescent units in all Icycler runs. Clade C and D reactions with identical plasmid concentrations differed in their $C_{\mathrm{T}}$ values by less then 0.5 , which allowed direct comparison of $C_{\mathrm{T}}(\mathrm{C})$ and $C_{\mathrm{T}}(\mathrm{D})$ of one sample.

In order to calculate the relative abundances of the two clades using the differences in $C_{\mathrm{T}}$ values, near-equal PCR efficiencies were required. PCR efficiency is $100 \%$ when the product doubles every cycle. Using a dilution series of a clade $\mathrm{C}$ and $\mathrm{D}$ sample, a $C_{\mathrm{T}}$ range of $18-32$ was obtained for each clade. The $\Delta C_{\mathrm{T}}$ was plotted against the $\log$ of the relative template concentrations and the slope of the linear regression line was -0.092 , which showed that PCR efficiencies were well matched and around $93 \%$.

Sensitivity is the ability to detect very low levels of DNA. The range of background clade detection was between the $C_{\mathrm{T}}$ of the dominant symbiont up to the cut-off cycle (set at 34, Fig. 2), thus the sensitivity varied per sample. On average, background clade copy numbers could be detected down to $0.004 \%$ of the total zooxanthella population, representing a ca. 1,000-fold greater sensitivity as compared to conventional assays. However, translating these values into relative abundances of the two clades requires caution because abundance is affected by copy number variability between individual zooxanthella cells (see next subheading). Thus, a more conservative overall estimate of the sensitivity is suggested, at minimally a 100fold increase over conventional methods.

\section{Copy number variability and intragenomic variants}

The limit of detection for single-cell real-time PCR runs was set at 500 copies, as the negative controls showed relatively high non-specific fluorescence. The fluorescent threshold was set at 0.1 normalised fluorescence in all Rotorgene runs. ITS1 copy number per cell ranged from $<500$ to $22,000 \quad(N=20)$ and from 2,300 to 12,000 $(N=13)$ for clade $\mathrm{C}$ and $\mathrm{D}$, respectively.

Based on bulk analysis of 100,000 isolated cells per colony, cell-average ITS1 copy number for clade C was $984 \pm 109$ (over four colonies) and 3,181 \pm 69 (over two colonies, mean \pm SE) for clade $\mathrm{D}$. Therefore, the $\mathrm{K}^{\mathrm{DC}}$ is estimated at three and reflects the difference in average copy number between clades $\mathrm{C}$ and $\mathrm{D}$.

The comparison between D:C ratios calculated from ITS1 and the cp23S (Table 3) showed good agreement within a factor of 10 . Therefore, D:C cell nr. ratios should be interpreted as "order of magnitude" estimates. In two cases the assays disagreed, where the ITS1 assay detected a background clade but the $23 \mathrm{~S}$ assay did not.

Re-assessing the incidence of background clades in scleractinian corals

Using the ITS1 assay, background clades were detected in $78 \%$ of 82 colonies, which based on previous SSCP analysis, were originally thought to harbor only a single symbiont clade (Table 1). A. millepora and S. pistillata had the highest frequency of backgrounds (20 out of 21 and 20 out of 22 colonies, respectively). A. tenuis (13 out of 18) and $T$. reniformis (11 out of 21) were less successful in acquiring/ maintaining backgrounds. For both A. millepora and $S$. pistillata, the only colonies without detectable background 
Table 3 Accuracy of ITS1 D:C ratio compared with an independent chloroplast marker

\begin{tabular}{lllll}
\hline Species & Location & $\begin{array}{l}\text { Cp 23S background } \\
\text { (D:C cell nr. ratio) }\end{array}$ & $\begin{array}{l}\text { ITS1 background } \\
\text { (D:C cell nr. ratio) }\end{array}$ & $\begin{array}{l}\text { Relative difference } \\
\text { (ITS1/23S) }\end{array}$ \\
\hline Acropora millepora & Darley Reef & $2.0 \times 10^{-4}$ & $6.8 \times 10^{-5}$ & 0.3 \\
& Darley Reef & $5.5 \times 10^{-4}$ & $1.9 \times 10^{-4}$ & 0.3 \\
& Miall Island & $4.5 \times 10^{2}$ & $8.9 \times 10^{1}$ & 0.2 \\
& Stone Island & $2.5 \times 10^{2}$ & $6.1 \times 10^{1}$ & 0.2 \\
Acropora tenuis & Chicken Reef & 0 & 0 & - \\
& Darley Reef & $2.0 \times 10^{-5}$ & $1.5 \times 10^{-5}$ & 0.7 \\
& Credlin Reef & 0 & $8.0 \times 10^{-4}$ & $\mathrm{x}$ \\
Stylophora pistillata & Chicken Reef & 0 & 0 & - \\
& Darley Reef & $3.0 \times 10^{-4}$ & $3.1 \times 10^{-4}$ & 1.0 \\
& Grassy Island & 0 & 0 & - \\
& Miall Island & $1.6 \times 10^{-1}$ & $2.9 \times 10^{-2}$ & 0.2 \\
& Magnetic Island & 0 & $4.8 \times 10^{-4}$ & $\mathrm{x}$ \\
\hline
\end{tabular}

clades were found at Chicken Reef, whereas A. tenuis and $T$. reniformis had colonies without backgrounds at all locations.

Symbiodinium clade $\mathrm{C}$ was the dominant endosymbiont at all locations for three out of the four species (A. tenuis, $S$. pistillata, T. reniformis), with average $\mathrm{D}: \mathrm{C}$ ratios ranging from $4.3 \times 10^{-6} \pm 1.5 \times 10^{-6}$ (mean $\pm \mathrm{SE}$ ) for $S$. pistillata at Credlin Reef to $5.8 \times 10^{-3} \pm 5.7 \times 10^{-3}$ for $T$. reniformis at Miall Island (Fig. 3b-d). Clade D dominance was found in six A. millepora colonies sampled at the inshore locations of Stone and Miall Islands (Fig. 3a). These colonies had a relatively high background level of clade $\mathrm{C}$ compared to the clade $\mathrm{D}$ backgrounds in the other samples (D:C ratio $\left.=7.4 \times 10^{1} \pm 1.2 \times 10^{1}\right)$. Again, it is cautioned that all D:C cell nr. ratios should be interpreted as "order of magnitude"' estimates.

Symbiodinium clade D backgrounds were detected in $71 \%$ of the colonies. The average clade $\mathrm{D}$ background density was 1 D-cell per 150-15,000 C-cells. Scleractinian corals have been estimated to harbor $\sim 1,500,000$ zooxanthella cells $\mathrm{cm}^{-2}$ of colony surface (Drew 1972), which translates into an average clade $\mathrm{D}$ background level of 100-10,000 cells $\mathrm{cm}^{-2}$.

No latitudinal gradient of D:C cell nr. ratio was apparent. Cross-comparison of off-shore and mid-shore reefs showed a tendency of $\mathrm{C}>\mathrm{D}$ on offshore reefs and $\mathrm{D}>\mathrm{C}$ on nearshore reefs in A. millepora, but not in the other species.

\section{Discussion}

Sensitivity, accuracy and caveats of the ITS1 real-time PCR assay

Real-time PCR can detect background or cryptic clades over eight orders of magnitude and is at least 100 times more sensitive than previously used techniques. However, the high copy number variability found between symbiont cells within both clades with the "single-cell" analyses means that the conversion of ITS1 copy numbers into an estimate of the number of symbiont cells has limited accuracy. On the other hand, the average ITS1 copy number estimates of clades $\mathrm{C}$ and $\mathrm{D}$, obtained from "bulked cell', analyses, were remarkably stable for each clade. These results indicate that cell-to-cell variation has only minor impact when enough cells are analyzed, but low-density background clade measurements will be more strongly affected. It should also be considered that the measured cell-to-cell variation might be an over-estimation of the real variation, caused by the difficult nature of single-cell amplifications. The approximate threefold discrepancy in average copy numbers between clades $\mathrm{C}$ and D led to the use of the correction factor $\mathrm{K}^{\mathrm{DC}}$ in an effort to get background abundance estimates as accurate as possible. The relative difference between the ITS 1 and $23 \mathrm{~S}$ assays varied within tenfold, which is still reasonable over the range measured, and indicates that $\mathrm{D}: \mathrm{C}$ cell nr. ratios are meaningful when interpreted as "order of magnitude", estimates.

The high agreement between the ITS1 and 23S assays indicated that the measured background clade signals were not due to intragenomic variation or PCR artifacts. For the two samples where the assays did not agree, it is assumed that the $23 \mathrm{~S}$ D-specific reactions failed as opposed to the absence of a D background, as it was noted that the $23 \mathrm{~S}$ assay was generally less robust compared to the ITS1 assay.

As a result of the high sensitivity of the real-time assay, it is possible that non-symbiotic zooxanthellae were detected, present as ingested cells or surface contaminants. Abundances of genuine free-living Symbiodinium are unknown, although progress is being made in detecting 
Fig. 3 The mean relative abundance of Symbiodinium clade $\mathrm{D}$ versus clade $\mathrm{C}$ in the four coral species at each of the sampling locations. Values should be regarded as "order of magnitude" estimates only (a) Acropora millepora

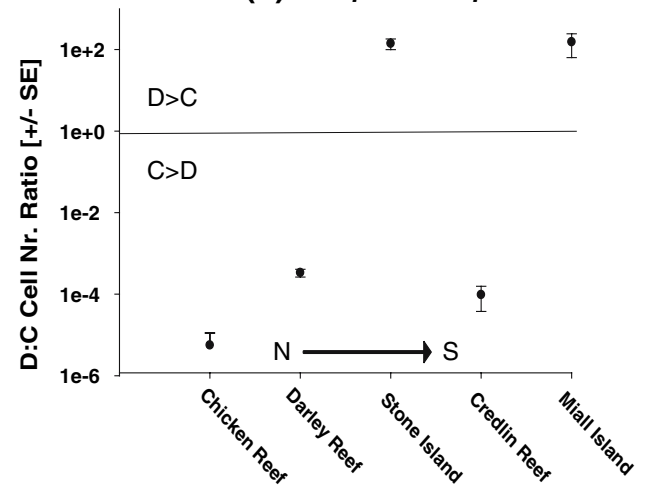

(c) Stylophora pistillata

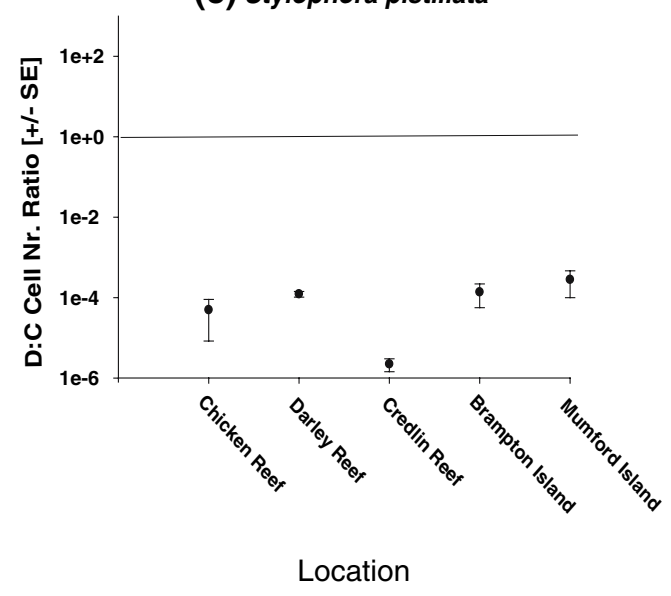

(b) Acropora tenuis

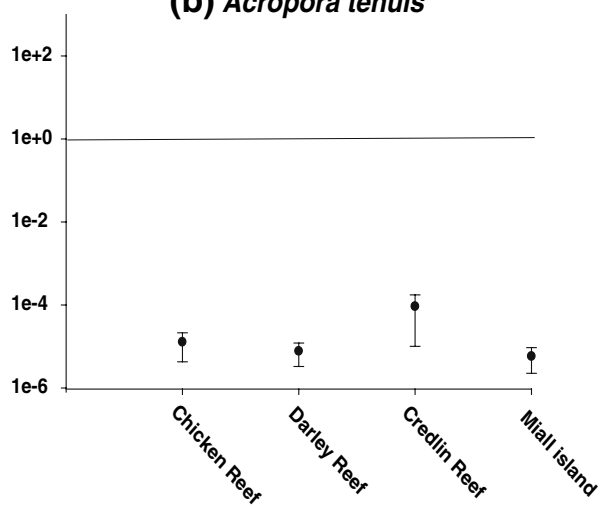

(d) Turbinaria reniformis

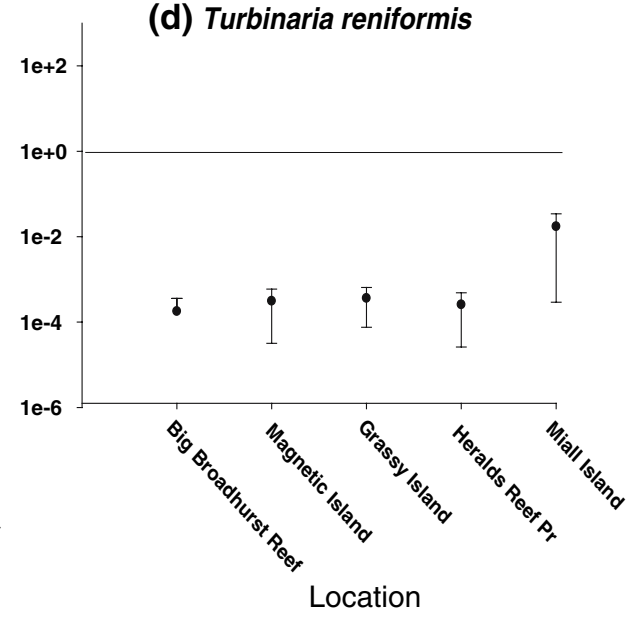

non-symbiotic, environmental populations (Coffroth et al. 2006). However, given the average background abundance detected in this study of 100-10,000 cells per $\mathrm{cm}^{2}$ of coral surface, it is unlikely, in our opinion, that these zooxanthellae were non-symbiotic.

\section{Significance of background clades}

Ninety-three percent of the colonies tested were dominated by clade $\mathrm{C}$ and $76 \%$ of these had a D background. A number of studies have shown that clade D symbionts are amongst the most thermo-tolerant types know to date, whereas clade C types are often relatively thermo-sensitive (Rowan 2004; Tchernov et al. 2004; Berkelmans and van Oppen 2006; Ulstrup et al. 2006). Clade D is also found on reefs that chronically experience unusually high temperatures (Fabricius et al. 2004) or that have recently been impacted by bleaching events (Baker et al. 2004), suggesting that temperature stress can favor clade D. It is proposed here that the clade D backgrounds detected in this study can potentially act as a safety-parachute, allowing corals to become more thermo-tolerant through symbiont shuffling as seawater temperatures rise due to global warming.
For species that have already been found to be dominated by clade D symbionts at some locations, such as $A$. millepora and T. reniformis, shuffling between these two clades seems a likely mechanism. Could shuffling act as a mechanism to acclimatize to increasing sea surface temperatures in more than a few species? At present this question remains open. It is likely that not all coral species will have a shuffling capacity, as certain coral species have a high symbiont stability (Goulet and Coffroth 2003b; Thornhill at al. 2006a, b) which may not allow them to shuffle even when recovering from bleaching (Thornhill et al. 2006a). However, the ratio between shuffling and non-shuffling species is currently unclear and needs further study.

The results of this study indicate that the potential for symbiont shuffling is higher than previously thought. However, symbiont shuffling is likely to represent a tradeoff and comes at a cost. First, coral colonies may have to bleach first before the background symbionts can proliferate (Baker 2001; Berkelmans and van Oppen 2006; Buddemeier and Fautin 1993), possibly causing high mortality in the process. Second, newly shuffled corals that have successfully recovered from bleaching are still likely 
to be impaired in growth and reproduction (Baird and Marshall 2002). Third, if the stressor disappears for a prolonged period of time, the corals may shuffle back to the original symbiont (Thornhill et al. 2006b), leaving them again vulnerable to subsequent bleaching events. Lastly, the extra heat-resistance that corals may gain by shuffling $\left(1-1.5^{\circ} \mathrm{C}\right)$ may be insufficient to help these populations cope with the predicted increases in average tropical sea temperatures over the next 100 years (Berkelmans and van Oppen 2006). Nevertheless, symbiont shuffling is likely to play a role in the way some corals cope with global warming conditions, leading to new competitive hierarchies and, ultimately, help shape the coral community assemblages of the future.

\section{Conclusions and future directions}

Real-time PCR can detect background clades over eight orders of magnitude, thus offering an assay that is at least 100 times more sensitive than previously used techniques. Furthermore, previous studies have failed to detect the majority of background clades because of the low sensitivity of the techniques used. This has led to an underestimation of the potential for symbiont shuffling.

The assay presented here should be used as a starting point to optimize the real-time PCR technique for coralSymbiodinium research. First, at present it only distinguishes between clades $\mathrm{C}$ and $\mathrm{D}$ and not between types within clades, i.e., $\mathrm{C}_{1}, \mathrm{C}_{2}$, etc. Because Symbiodinium physiology is highly diverse and thermally tolerant types are known to exist within a single clade (Tchernov et al. 2004), future efforts will need to be directed towards the development of type-specific real-time PCR assays. Second, while rDNA-ITS continues to be the main marker in use, it has many unfavorable properties associated with its multi-copy nature. The development of novel single-copy markers for Symbiodinium should be a research priority and may become available from EST libraries that are currently under development.

The application of this technique in broadscale surveys for background Symbiodinium clades/types in many coral species, will allow the re-evaluation of the prevalence of background symbionts. The next challenge will be to decipher how symbiont shuffling is regulated (by the coral host, through competition between symbiont types inside the host tissues, and/or by environmental factors), and to understand how many corals harboring multiple symbiont types are able to undergo temporal changes in their symbiont communities.

Acknowledgments We thank K. Ulstrup for supplying the coral DNA collection for the species T. reniformis, and B. Küst (University of Groningen, The Netherlands) for help with the real-time PCR measurements. We also thank the four anonymous reviewers whose comments greatly improved the manuscript. This work was funded by NWO-WOTRO (The Netherlands), Project Nr. W84-576, and further supported by the Australian Institute of Marine Science.

\section{References}

Apprill AM, Gates RD (2007) Recognizing diversity in coral symbiotic dinoflagellate communities. Mol Ecol 16:1127-1134

Arnheim N, Krystal M, Wilson G, Ryder O, Zimmer E (1980) Molecular evidence for genetic exchanges among ribosomal genes on nonhomologous chromosomes in man and apes. Proc Natl Acad Sci USA 77:7323-7327

Baird AH, Marshall PA (2002) Mortality, growth and reproduction in scleractinian corals following bleaching on the Great Barrier Reef. Mar Ecol Prog Ser 237:133-141

Baker AC (2001) Reef corals bleach to survive change. Nature 411:765-766

Baker AC (2003) Flexibility and specificity in coral-algal symbiosis: diversity, ecology, and biogeography of Symbiodinium. Annu Rev Ecol Evol Syst 34:661-689

Baker AC, Starger CJ, McClanahan T, Glynn PW (2004) Corals' adaptive response to climate change. Nature 430:741

Berkelmans R, van Oppen MJH (2006) The role of zooxanthellae in the thermal tolerance of corals: a 'nugget of hope' for coral reefs in an era of climate change. Proc R Soc Lond B 273:2305-2312

Bhagooli R, Hidaka M (2003) Comparison of stress susceptibility of in hospite and isolated zooxanthellae among five coral species. J Exp Mar Biol Ecol 291:181-197

Buddemeier RW, Fautin DG (1993) Coral bleaching as an adaptive mechanism. Bioscience 43:320-325

Chen CA, Wang AT, Fang LS, Yang YW (2005) Fluctuating algal symbiont communities in Acropora palifera (Scleractinia: Acroporidae) from Taiwan. Mar Ecol Prog Ser 295:113-121

Coffroth MA, Santos SR (2005) Genetic diversity of symbiotic dinoflagellates in the genus Symbiodinium. Protist 156:19-34

Coffroth MA, Lewis CF, Santos SR, Weaver JL (2006) Environmental populations of symbiotic dinoflagellates in the genus Symbiodinium can initiate symbioses with reef cnidarians. Curr Biol 16:R985-R987

Diekmann OE, Bak RPM, Tonk L, Stam WT, Olsen JL (2002) No habitat correlation of zooxanthellae in the coral genus Madracis on a Curacao reef. Mar Ecol Prog Ser 227:221-232

Dover G (1982) A molecular drive through evolution. Bioscience 32:526-533

Drew EW (1972) The biology and physiology of algal-invertebrate symbioses. II. The density of symbiotic algal cells in a number of hermatypic hard corals and alcyonarians from various depths. J Exp Mar Biol Ecol 9:71-75

Fabricius KE, Mieog JC, Colin PL, Idip D, van Oppen MJH (2004) Identity and diversity of coral endosymbionts (zooxanthellae) from three Palauan reefs with contrasting bleaching, temperature and shading histories. Mol Ecol 13:2445-2458

Goulet TL (2006) Most corals may not change their symbionts. Mar Ecol Prog Ser 321:1-7

Goulet TL, Coffroth MA (2003a) Genetic composition of zooxanthellae between and within colonies of the octocoral Plexaura kuna, based on small subunit rDNA and multilocus DNA fingerprinting. Mar Biol 142:233-239

Goulet TL, Coffroth MA (2003b) Stability of an octocoral-algal symbiosis over time and space. Mar Ecol Prog Ser 250:117124 
Govindaraju DR, Cullis CA (1992) Ribosomal DNA variation among populations of a Pinus rigida Mill (Pitch Pine) ecosystem.1. Distribution of copy numbers. Heredity 69:133-140

Iglesias-Prieto R, Trench RK (1997) Acclimation and adaptation to irradiance in symbiotic dinoflagellates. II. Response of chlorophyll-protein complexes to different photon-flux densities. Mar Biol 130:23-33

Kinzie RA, Takayama M, Santos SR, Coffroth MA (2001) The adaptive bleaching hypothesis: experimental tests of critical assumptions. Biol Bull 200:51-58

LaJeunesse TC (2002) Diversity and community structure of symbiotic dinoflagellates from Caribbean coral reefs. Mar Biol 141:387-400

Lewis CL, Coffroth MA (2004) The acquisition of exogenous algal symbionts by an octocoral after bleaching. Science 304:14901492

Little AF, van Oppen MJH, Willis BL (2004) Flexibility in algal endosymbioses shapes growth in reef corals. Science 304:14921494

Pochon X, Montoya-Burgos JI, Stadelmann B, Pawlowski J (2006) Molecular phylogeny, evolutionary rates, and divergence timing of the symbiotic dinoflagellate genus Symbiodinium. Mol Phylogenet Evol 38:20-30

Robison JD, Warner ME (2006) Differential impacts of photoacclimation and thermal stress on the photobiology of four different phylotypes of Symbiodinium (Pyrrhophyta). J Phycol 42:568579

Rogers SO, Bendich AJ (1987) Ribosomal-RNA genes in plants-variability in copy number and in the intergenic spacer. Plant Mol Biol 9:509-520

Rowan R (2004) Thermal adaptation in reef coral symbionts. Nature 430:742
Tchernov D, Gorbunov MY, de Vargas C, Yadav SN, Milligan AJ, Häggblom M, Falkowski PG (2004) Membrane lipids of symbiotic algae are diagnostic of sensitivity to thermal bleaching in corals. Proc Natl Acad Sci USA 101:13531-13535

Thornhill DJ, Fitt WK, Schmidt GW (2006a) Highly stable symbioses among western Atlantic brooding corals. Coral Reefs 25:515519

Thornhill DJ, LaJeunesse TC, Kemp DW, Fitt WK, Schmidt GW (2006b) Multi-year, seasonal genotypic surveys of coral-algal symbioses reveal prevalent stability or post-bleaching reversion. Mar Biol 148:711-722

Ulstrup KE, van Oppen MJ (2003) Geographic and habitat partitioning of genetically distinct zooxanthellae (Symbiodinium) in Acropora corals on the Great Barrier Reef. Mol Ecol 12:34773484

Ulstrup KE, Berkelmans R, Ralph PJ, van Oppen MJH (2006) Variation in bleaching sensitivity of two coral species across a latitudinal gradient on the Great Barrier Reef: the role of zooxanthellae. Mar Ecol Prog Ser 314:135-148

van Oppen MJH, Mahiny AJ, Done TJ (2005) Geographic distribution of zooxanthella types in three coral species on the Great Barrier Reef sampled after the 2002 bleaching event. Coral Reefs 24:482-487

Wilson $\mathrm{K}$, Li $\mathrm{Y}$, Whan $\mathrm{V}$, Lehnert S, Byrne $\mathrm{K}$, Moore S, Pongsomboon S, Tassanakajon A, Rosenberg G, Ballment E (2002) Genetic mapping of the black tiger shrimp Penaeus monodon with amplified fragment length polymorphism. Aquaculture 204:297-309

Zhang Q, Maroof MA, Allard RW (1990) Effects on adaptedness of variations in ribosomal DNA copy number in populations of wild barley (Hordeum vulgare ssp. Spontaneum). Proc Natl Acad Sci USA 87:8741-8745 